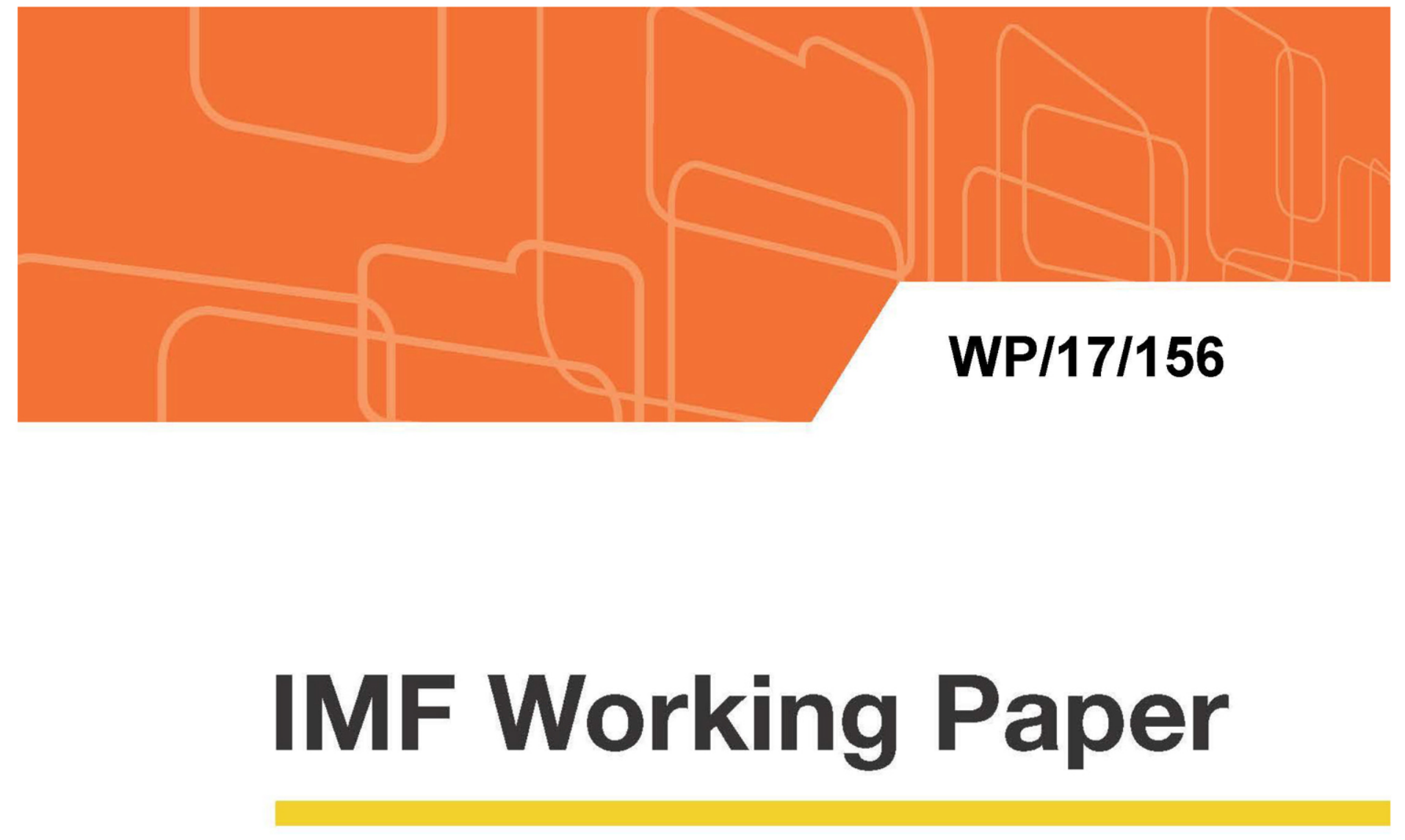

\title{
The Informal Economy in Sub-Saharan Africa: Size and Determinants
}

Leandro Medina, Andrew Jonelis, and Mehmet Cangul

IMF Working Papers describe research in progress by the author(s) and are published to elicit comments and to encourage debate. The views expressed in IMF Working Papers are those of the author(s) and do not necessarily represent the views of the IMF, its Executive Board, or IMF management. 


\section{WP/17/156}

\section{IMF Working Paper}

\section{The Informal Economy in Sub-Saharan Africa: Size and Determinants}

Leandro Medina, Andrew Jonelis, and Mehmet Cangul

IMF Working Papers describe research in progress by the author(s) and are published to elicit comments and to encourage debate. The views expressed in IMF Working Papers are those of the author(s) and do not necessarily represent the views of the IMF, its Executive Board, or IMF management. 
IMF Working Paper

\title{
The Informal Economy in Sub-Saharan Africa: Size and Determinants
}

\author{
Prepared by Leandro Medina, Andrew Jonelis, and Mehmet Cangul ${ }^{1}$ \\ Authorized for distribution by Ali Mansoor
}

July 2017

\begin{abstract}
IMF Working Papers describe research in progress by the author(s) and are published to elicit comments and to encourage debate. The views expressed in IMF Working Papers are those of the author(s) and do not necessarily represent the views of the IMF, its Executive Board, or IMF management.
\end{abstract}

\begin{abstract}
The multiple indicator-multiple cause (MIMIC) method is a well-established tool for measuring informal economic activity. However, it has been criticized because GDP is used both as a cause and indicator variable. To address this issue, this paper applies for the first time the light intensity approach (instead of GDP). It also uses the Predictive Mean Matching (PMM) method to estimate the size of the informal economy for Sub-Saharan African countries over 24 years. Results suggest that informal economy in Sub-Saharan Africa remains among the largest in the world, although this share has been very gradually declining. It also finds significant heterogeneity, with informality ranging from a low of 20 to 25 percent in Mauritius, South Africa and Namibia to a high of 50 to 65 percent in Benin, Tanzania and Nigeria.
\end{abstract}

JEL Classification Numbers: E26, E01, H26, H32, K42, P24, O17

Keywords: Informal economy, MIMIC estimation methods, Sub-Saharan Africa.

Author's E-Mail Address: 1medina@imf.org, andrew.jonelis@uky.edu,mcangul@imf.org

\footnotetext{
${ }^{1}$ The authors wish to thank Ali Mansoor for guidance and support, Celine Allard, David Owen, David Robinson, Cemile Sancak, Friedrich Schneider, Abe Selassie, and participants of the 2017 IMF Analytical Corner for useful comments. The authors also wish to thank Sergiy Nesterko and Roee Gutman for their invaluable advice on alternative empirical methods.
} 


\section{Contents}

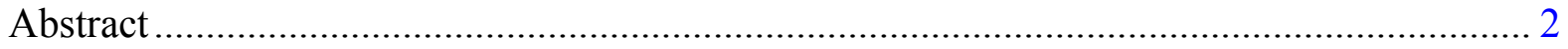

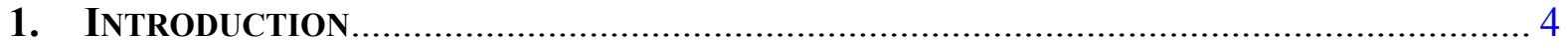

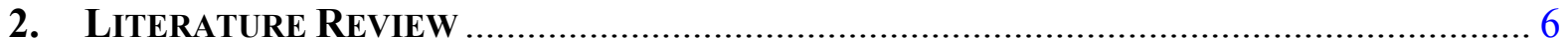

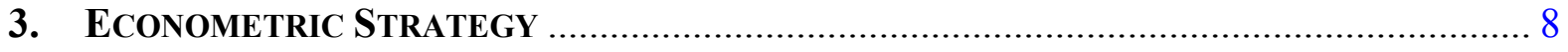

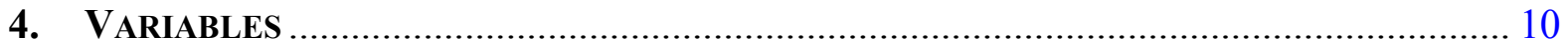

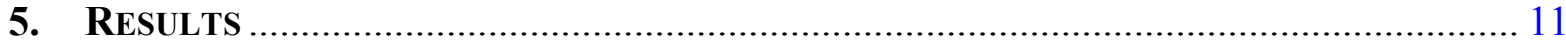

A.MIMIC Estimation Results ...................................................................................... 11

B.Estimation of the Size of the Informal Economy …………......................................... 13

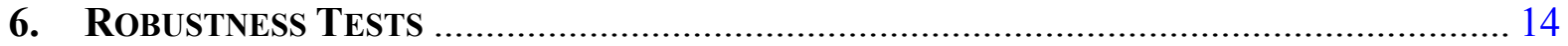

A. Estimating the Size of the Informal Economy Using Predictive Mean Matching......... 14

B. Estimating the Size of the Informal Economy Using Traditional MIMIC Approach (a la Schneider, 2010) ................................................................................................. 16

C. Comparison with Countries' National Accounts Statistics............................................. 18

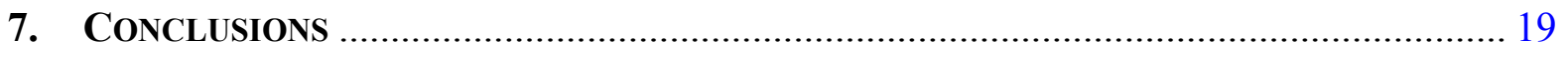

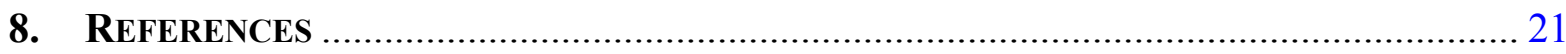




\section{INTRODUCTION}

The characterization of the informal economy has been debated in both policy and academic circles. There is no standard definition of the informal economy in the literature, and terms such as shadow economy, black economy and unreported economy have been used to define it.

According to Feige (2005), the phrase informal economy has been used frequently, and inconsistently; he argues that the informal economy comprises economic activities that circumvent costs and are excluded from the benefits and rights incorporated in laws and administrative rules covering property relationships, commercial licensing, labor contracts, torts, financial credit, and social systems.

Measuring informality is important given that workers in informal conditions have little or no social protection or employment benefits; and these conditions undermine inclusiveness in the labor market. Additionally, informal economic activity severely limits tax revenues for developing countries most in need of a stable tax base. This suggests that developing economies have an incentive to understand the scale of informal economic activity and how to shift production from the informal to the formal sector.

Different methods have been proposed to estimate the size of the informal economy. Direct approaches, mostly based on surveys and samples, rely on voluntary replies, or tax auditing and other compliance methods to measure the informal economy. The results are sensitive to how the questionnaire is formulated and therefore unlikely to capture all informal activities.

Indirect approaches, also called indicator approaches, use indirect information to estimate the size of the informal economy. For example, the discrepancy between the official and actual labor force approach states that a decline in labor force participation in the official economy can be seen as an indication of an increase in the size of the informal economy, if total labor force participation is assumed to be constant. Most direct and indirect methods consider just one indicator for all effects of the informal economy.

A growing literature uses the MIMIC model (See Schneider and Enste, 2000). Among the MIMIC's main features: (i) the model explicitly considers multiple causes of the existence and growth of the informal economy, as well as multiple effects of the informal economy over time, whereas other methods mainly use one indicator of the size of informal economy (e.g. electricity consumption), and (ii) the model is based on unobserved variables, which considers a set of causes and indicators of the unobserved phenomenon to be measured.

However, recently, MIMIC has been subject of criticism for: (i) the use of GDP (GDP per capita and growth of GDP per capita) as cause and indicator variables, (ii) the fact that the methodology relies on another independent study to calibrate from standardized values to size of informal economy in percent of GDP, and (iii) the estimated coefficients are sensitive to alternative specifications, the country sample and time span chosen. 
This paper contributes to the literature and addresses the concerns of endogeneity as well as using predictive mean matching as a robustness check for measuring the size of the informal economy in Sub-Saharan African countries. Specifically, by:

(a) using a modified version of the standard Multiple Indicator-Multiple Cause (MIMIC) model. This version, addresses endogeneity concerns for the use of GDP by using satellite data on the night light intensity instead of GDP as an indicator variable proxying the size of the economy.

(b) Estimating the size of the informal economy by using a completely independent method, the Predictive Mean Matching method (PMM) by Rubin (1987). This not only tests the robustness of the modified MIMIC with an alternative econometric technique but also addresses a long and controversial discussion on how to calibrate the relative MIMIC estimates of the informal economy (compare Hashimzade and Heady (2016), Feige (2016a and 2016b), and Schneider (2016).

(c) Finally, by comparing these results with the official estimations from countries' national account statistics.

We believe this is the first time that such a combination of methodologies, which includes modified MIMIC using satellite data on night light intensity, and PMM has been used to generate robust estimates of the size of the informal economy, which we compare to estimates provided by national authorities.

Results suggest that there is significant heterogeneity in the size of informality in SSA, ranging from a low of 20 to 25 percent of formal sector output in Mauritius, South Africa and Namibia to a high of 50 to 65 percent in Benin, Tanzania and Nigeria. Additionally, that the share of informal economic activity in Sub-Saharan Africa remains among the largest in the world, although this share has been very gradually declining.

Results also suggest that broadly, informality seems to fall with the level of income likely reflecting higher government capacity and better incentives toward formality in higher income countries. This global trait also holds for Sub-Saharan Africa, as the informal economy averages 40 percent in the region's low income countries and 35 percent for its middle income countries. Although, oil exporters and fragile countries are, everything else equal, more likely to harbor informality, with an informal economy well above 40 percent of GDP, regardless of the level of income per capita.

To verify the validity and robustness of the estimates, we have cross-checked them using an alternative and fully independent econometric approach, the Multiple Imputations Predictive Mean Matching (MIPMM), developed by Rubin D.B. The MIMIC results are found to be robust when cross-checked with MIPMM results. This alternative method treats informality as a missing data issue. The objective is to match the countries where data exist to the those where data are missing by using characteristics that would be relevant to the size of the 
informal economy. ${ }^{2}$ When using this procedure, countries are ordered in groups based on the size of the informal economy. These groups are broadly aligned with our estimates from the MIMIC.

The robustness of MIMIC results is also checked against the estimates of Statistical Agencies of eight sub-Saharan African countries for which information is readily available. The rank correlation is high — about 80 percent - between MIMIC results and these estimates. Although these agencies provide estimates of the size of the informal economy, the data generated by MIMIC is still useful. First, not all countries publish the information. Second, methodologies and sampling methods may affect the comparability of cross-country estimates. Finally, estimates may be rooted in approaches that fail to take account of recent changes in the domestic economy. In contrast, MIMIC produces panel data for most countries that is comparable and can be used to test statistical relationships.

\section{LiteratURE REVIEW}

This section follows Schneider and Este (2002), as well as Feld and Schneider (2010), and mostly describes the main methodologies used to measure the informal economy, highlighting their advantages and drawbacks. These approaches can be divided into direct or indirect (including the model-based ones).

The most common direct approaches to measuring the size of the informal economy rely on surveys and samples based on voluntary replies, or tax auditing and other compliance methods. While providing great detail about the structure of the informal economy, the results are sensitive to the way the questionnaires are formulated, as well as respondents' willingness to cooperate with forthright and truthful answers. Consequently, surveys are unlikely to capture all informal activities. ${ }^{3}$

Indirect approaches, alternatively called "indicator" approaches, are mostly macroeconomic in nature. These are in part based on: (i) the discrepancy between national expenditure and income statistics; (ii) the discrepancy between the official and actual labor force; (iii) the "electricity consumption" approach of Kauffman and Kaliberda (1996); (iv) the "monetary transaction" approach of Feige (1979); (v) the "currency demand" approach of Cagan (1958) and others; and (vi) the "Multiple Indicators, Multiple Causes" (MIMIC) where the informal economy is considered as a latent variable. Specifically:

(i) Discrepancy between national expenditure and income statistics: If those working in the informal economy were able to hide their incomes for tax purposes but not their expenditure, then the difference between national income and national

\footnotetext{
2 There were 49 countries that were identified to have survey-based estimates of the size of their informal economies, including nine in Sub-Saharan Africa.

3 See Isanchen and Strom (1985), Witte (1987), and Mogensen et al. (1995).
}

(continued...) 
expenditure estimates could be used to approximate the size of the informal economy. This approach assumes that all the components of the expenditure side are measured without error and constructed so that they are statistically independent from income factors. ${ }^{4}$

(ii) Discrepancy between official and actual labor force: If the total labor force participation is assumed to be constant, a decline in official labor force participation can be interpreted as an increase in the importance of the informal economy. Since fluctuation in the participation rate might have many other explanations, such as the position in the business cycle, difficulty in finding a job, as well as education and retirement decisions, these estimates represent weak indicators of the size of the informal economy. ${ }^{5}$

(iii) Electricity approach: Kaufmann and Kaliberda (1996) endorse the idea that electricity consumption is the single best physical indicator of overall (official and unofficial) economic activity. Using findings that indicate the electricity-overall GDP elasticity is close to one, these authors suggest using the difference between growth of electricity consumption and growth of official GDP as a proxy for the growth of the informal economy. This method is simple and appealing, but has many drawbacks, including: (i) not all informal economy activities require a considerable amount of electricity (e.g. personal services) or the use of other energy sources (like coal, gas, etc.), hence only part of the informal economy growth is captured; and (ii) the electricity-overall GDP elasticity might vary significantly across countries and over time. ${ }^{6}$

(iv) Transaction approach: Using Fischer's quantity equation, Money*Velocity $=$ Prices*Transactions, and assuming that there is a constant relationship between the money flows related to transactions and the total (official and unofficial) value added, i.e. Prices $*$ Transactions $=k$ (official GDP + informal economy), it is reasonable to derive the following equation Money $*$ Velocity $=k$ (official GDP + informal economy). The stock of money and official GDP estimates are known, and money velocity can be estimated. Thus, if the size of the informal economy as a ratio of the official economy is known for a benchmark year, then the informal economy can be calculated for the rest of the sample. Although theoretically attractive, this method has several weaknesses, for instance: (i) the assumption of $k$ constant over time seems quite arbitrary; and (ii) other factors like the

\footnotetext{
${ }^{4}$ See for example MacAfee (1980), and Yoo and Hyun (1998).

${ }^{5}$ See for example Contini (1981), Del Boca (1981), and O’Neil (1983).

${ }^{6}$ See for example Del Boca and Forte (1982), Portes (1996) and Johnson et al. (1997).
}

(continued...) 
development of checks and credit cards could also affect the desired amount of cash holdings and thus velocity. ${ }^{7}$

(v) Currency demand approach: Assuming that informal transactions take the form of cash payments, in order not to leave an observable trace for the authorities, an increase in the size of the informal economy will, consequently, increase the demand for currency. To isolate this "excess" demand for currency, Tanzi (1980) suggests using a time series approach in which currency demand is a function of conventional factors, such as the evolution of income, payment practices and interest rates, and factors causing people to work in the informal economy, like the direct and indirect tax burden, government regulation and the complexity of the tax system. However, there are several problems associated with this method and its assumptions: (i) this procedure may underestimate the size of the informal economy, because not all transactions take place using cash as means of exchange; (ii) increases in currency demand deposits may occur because of a slowdown in demand deposits withdrawals rather than an increase in currency used in informal activities; (iii) it seems arbitrary to assume equal velocity of money in both types of economies; and (iv) the assumption of no informal economy in a base year is arguable. ${ }^{8}$

(vi) Multiple Indicators, Multiple Causes (MIMIC) approach: This method explicitly considers several causes, as well as the multiple effects, of the informal economy. The methodology makes use of the associations between the observable causes and the effects of an unobserved variable, in this case the informal economy, to estimate the variable itself (Loayza, 1997). ${ }^{9}$

\section{ECONOMETRIC STRATEGY}

Most of the methods described above consider only one (either direct or indirect) indicator of the informal economy, such as electricity consumption or money demand. However, there may exist more than one manifestation or symptom of the informal economy showing up simultaneously.

This paper uses the MIMIC approach, as it explicitly considers various causes, as well as several effects of the informal economy. The model exploits the associations between

\footnotetext{
${ }^{7}$ See for example Feige (1979), Boeschoten and Fase (1984) and Langfeldt (1984).

${ }^{8}$ See for example Cagan (1958), Gutmann (1977), Tanzi (1980, 1983), Schneider (1997) and Johnson et al. (1998).

${ }^{9}$ See Schneider (2010); Abdih and Medina (2016), and Vuletin (2009).
}

(continued...) 
observable causes and effects of the unobserved informal economy to estimate the size of the informal economy itself. ${ }^{10}$ The model can be described as:

$$
\begin{aligned}
& y=\lambda I E+\varepsilon \\
& I E=\gamma^{\prime} x+v
\end{aligned}
$$

where $I E$ is the unobservable latent variable, $y^{\prime}=\left(y_{1}, \ldots, y_{p}\right)$ is a vector of indicators for $I E$, $x^{\prime}=\left(x_{1}, \ldots, x_{q}\right)$ is a vector of causes of $I E, \lambda$ and $\gamma$ are the $(p x 1)$ and $(q x 1)$ vectors of the parameters, and $\varepsilon$ and $v$ are the (px1) and scalar errors. Equation (1) relates the informal economy to its indicators, while equation (2) associates the informal economy with a set of observable causes. Assuming that the errors are normally distributed and mutually uncorrelated with $\operatorname{var}(v)=\sigma_{v}^{2}$ and $\operatorname{cov}(\varepsilon)=\Theta_{\varepsilon}$, the model can be solved for the reduced form as a function of observable variables by combining equations (1) and (2):

$$
y=\pi x+\mu
$$

where $\pi=\lambda \gamma^{\prime}, \mu=\lambda v+\varepsilon$ and $\operatorname{cov}(\mu)=\lambda \lambda^{\prime} \sigma_{v}^{2}+\Theta_{\varepsilon}$.

As $y$ and $x$ are data vectors, equation (3) can be estimated by maximum likelihood using the restrictions implied in both the coefficient matrix $\pi$ and the covariance matrix of the errors $\mu$. Since the reduced form parameters of equation (3) remain unaltered when $\lambda$ is multiplied by a scalar and $\gamma$ and $\sigma_{v}^{2}$ are divided by the same scalar, the estimation of equations (1) and (2) requires a normalization of the parameters in equation (1), and a convenient way to achieve this is to constrain one element of $\lambda$ to some pre-assigned value.

Since the estimation of $\lambda$ and $\gamma$ is obtained by constraining one element of $\lambda$ to an arbitrary value, it is useful to standardize the regression coefficients $\hat{\lambda}$ and $\hat{\gamma}$ as $\hat{\lambda}^{s}=\hat{\lambda}\left(\frac{\hat{\sigma}_{I E}}{\hat{\sigma}_{y}}\right)$ and $\hat{\gamma}^{s}=\hat{\gamma}\left(\frac{\hat{\sigma}_{x}}{\hat{\sigma}_{I E}}\right)$

The standardized coefficient measures the expected change (in standard-deviation units) of the dependent variable due to a one standard-deviation change of a given explanatory variable, when all other explanatory variables are held constant. Using the estimates of the $\gamma^{s}$ vector and setting the error term $v$ to its mean value of zero, the predicted values for the informal economy can be estimated using equation (2). Then, by using information from various independent studies regarding the specific size of the informal economy measured in percent of GDP, the ordinal within-sample predictions for the informal economy can be converted into percentages of GDP.

\footnotetext{
${ }^{10}$ See Loayza (1997).
} 


\section{VARIABLES}

As explained in the previous section, MIMIC uses indirect measures of the entire economy to derive the size of the informal economy that is "unobserved" in the surveys that form the basis of the national accounts. It estimates the unobserved informal sector by explicitly considering the multiple causes for the existence and growth of the informal economy, as well as its multiple effects (see Figure 1).

The specialized literature highlights the tax burden or government distortionary policies, labor market rigidities, lack of institutional quality, and product and financial market rigidities as the main causes (see, for example, Schneider et al. (2010), Feldmann (2009), and Schneider and Enste (2000)).

The MIMIC model in this paper covers a sample of 140 countries over the 1991-2014 interval. Moreover, it has been refined to respond to past criticisms on the methodology. ${ }^{11}$

Our MIMIC estimation relies on the following observable drivers of the informal economy:

- $\quad$ fiscal freedom, a measure of tax burden on the economy. Everything else equal, a larger tax burden is likely to encourage more economic activity to remain in the informal economy

- $\quad$ institutions, as lack of respect for the law would encourage informal activity

- unemployment, as lack of work in the formal sector would force some to seek work in informal economic activity, and

- $\quad$ trade openness, as international trade increases, it would be harder to hide trade from the authorities.

MIMIC also uses measurable indicators of the informal economy, namely,

- $\quad$ currency as a fraction of broad money, as people engaged in the informal economy usually conduct their activities in cash

- labor force participation, as a decline in official labor force participation could signal some giving up searching for work in the formal sector, and

- $\quad$ a measure of the size of the economy using night lights. Instead of using GDP per capita and growth of GDP per capita as cause and indicator variables, we use the night lights approach by Henderson, Storeygard, and Weil (2012) to independently capture

\footnotetext{
${ }^{11}$ The main criticism is that most studies using this methodology are subject to endogeneity, as they use GDP in both sides of the MIMIC equation (i.e., GDP per capita as cause and growth of GDP per capita indicator).
} 
economic activity. In their paper, they use data on light intensity from outer space as a proxy for the "true" economic growth achieved by countries. They also use the estimated elasticity of light intensity with respect to economic growth to produce new estimates of national output for countries deemed to have low statistical capacity. Therefore, by using the night lights approach we address MIMIC criticisms related to the endogeneity of GDP. This addresses criticisms related to endogeneity of GDP in a novel way, which is totally independent from problematic GDP measures traditionally used.

\section{RESULTS}

\section{A. MIMIC Estimation Results}

The benchmark MIMIC specification, is represented in Figure 1. The fiscal freedom index, institutions (rule of law), unemployment, and trade openness are the cause variables of the informal economy; while currency (M0/M1), labor force participation, and the size of the economy (night lights) are the indicator variables.

The coefficients on the causal and indicator variables have the expected signs, and are statistically significant (mostly at the 1 or 5 percent level). Specifically, a one standard deviation increase in the fiscal freedom index, institutions (rule of law), unemployment, and trade openness increase the size of the informal economy by $-0.15,-0.07,0.07$ and -0.18 standard deviations, respectively.

Alternative MIMIC specifications are considered for robustness purposes (See Tables 1, 2, and 3) and we find consistent results across the specifications.

In Table 1, we use data on all countries in our sample over the time period. One consistent result to note is that a standard deviation increase in trade openness decreases the size of the informal economy by approximately 0.17 standard deviations across all specifications. This provides evidence that we believe shows countries with more trade have more of that economic activity recorded by national authorities and included in the formal sector with all accompanying regulations and taxes. The effect of the unemployment rate is also consistently estimated as a one standard deviation increase lead to an approximate 0.07 increase in the informal sector. This also confirms our prior that as less formal sector jobs are available, workers will choose to seek work in the informal sector.

In the first two specifications, the size of government is also consistently estimated where a one standard deviation increase leads to a 0.1 increase in the informal economy. The magnitude of this effect drops vastly when we include a measure of government stability. This potentially shows that more stable governments may provide a better business environment for the formal sector and thus the distortionary effect of greater government size is somewhat mitigated. In the next three specifications, we consider fiscal freedom as an alternative measure of the government's distortionary activity shifting economic activity from the formal to informal sector. Across these specifications, we find a consistent estimate where a one 
standard deviation increase in fiscal freedom decreases the share of informal economic activity by 0.16 standard deviations. The magnitude on this coefficient remains similar even when including government stability, suggesting it is capturing the distortionary effect of taxation better than the size of government.

In specifications one and four, we find that the rule of law is significant and a one standard deviation increase in the rule of law decreases the share of informal economic activity by 0.06 standard deviations. We find no statistical significance from our measure of control on corruption, but the sign of the coefficient is in line with our prior that corruption would encourage informal economic activity. Lastly, as mentioned earlier, government stability is statistically significant and decreases the share of informal economic activity. For the indicators of informal economic activity, we standardize the coefficient on currency to be one, as is standard in the literature (see Schneider 2010). Our other two indicators of informal economic activity are the labor force participation rate and the night light density as a proxy of total economic activity. Across all specifications we find that informal economic activity is statistically significant and decreases both labor force participation and night light density. The magnitudes of the coefficients vary across specifications, but this is likely the result of using different measures for the distortionary effect of government in the economy. We also find that informal economic activity decreases night light intensity across all specifications.

Tables 2 and 3 repeat the estimation from Table 1, but we split the sample into developing and advanced economies. The results of this robustness check are largely consistent with Table 1, but there are some interesting differences to note. The effect of trade openness on informal economic activity is statistically significant across all specifications for developing countries with a similar magnitude to the results for the entire sample, while the effect for advanced economies has a larger magnitude when found statistically significant. This is likely due to advanced economies having better monitoring over the goods and services crossing their borders.

In Table 2, we do not find any statistical significance for the effect of the unemployment rate on informal economic activity. This could be due to the labor market between formal and informal sectors in developing countries being more fluid and when labor market conditions deteriorate in the formal sector they also deteriorate in the informal sector. Alternatively, in Table 3, we find that the unemployment rate has a statistically significant and negative effect on informal economic activity. We believe this may be caused by a complementarity between informal economic activities and formal economic activity. Those who lose their jobs in advanced economies could be the largest consumers in the informal economy.

Our two measures of the distortionary effect of government have similar significance and magnitude for the sample of developing economies. However, we find the magnitude of the effect for advanced economies to be nearly double the effect for the whole sample and developing economies. This result suggests that the distortionary effect of government taxation matters more for advanced economies and the effect is less for developing economies. 
One last difference from our causal variables is that the rule of law is found to be statistically significant for the advanced economies and not for developing economies, but government stability is significant for the developing economies and not the advanced economies. This is another interesting result suggesting that in developing economies having a stable government - whether democratic or autocratic - matters more for encouraging formal economic activity, but for advanced economies, consistent "rules of the game" matters for encouraging formal economic activity.

Now considering the indicator variables of informal economic activity, we find that a greater share of informal economic activity decreases labor force participation and is statistically significant across all specifications in Tables 2 and 3. However, we find another interesting difference between advanced and developing economies for the effect of informal economic activity on night light intensity. For the developing economies, we find that greater informal economic activity leads to a statistically significant decrease in night light density, while more informal activity leads to an increase in night light density for advanced economies. We hypothesize a couple of reasons this may be the case: first, citizens in advanced economies may be able to better hide their informal economic activity, and second, a number of informal economic activities in advanced economies may take place at night thereby increasing the night light intensity.

\section{B. Estimation of the Size of the Informal Economy}

Our estimates suggest that there is significant heterogeneity in the size of informality in SSA (Figure 2), ranging from a low of 20 to 25 percent in Mauritius, South Africa and Namibia to a high of 50 to 65 percent in Benin, Tanzania and Nigeria.

The share of informal economic activity in Sub-Saharan Africa remains among the largest in the world, although this share has been very gradually declining, as seems to be the case globally (Figure 3). The SSA unweighted average share of informality reached almost 38 percent of GDP over 2010-14. This is surpassed only by Latin America, at 40 percent of GDP and compares with 34 percent of GDP in South Asia, and 23 percent of GDP in Europe. In OECD countries, the informal sector is estimated to account for 17 percent of GDP.

Broadly, informality seems to fall with the level of income likely reflecting higher government capacity and better incentives toward formality in higher income countries. It averages 40 percent of GDP in low income countries over 2010-2014, whereas it only accounts for 32 percent of GDP in emerging economies and 18 percent of GDP in advanced economies.

That global trait also holds for Sub-Saharan Africa, as the informal economy averages 40 percent in the region's low income countries and 35 percent for its middleincome countries. Nonetheless, a different characterization seems to trump those considerations: oil exporters 
and fragile countries are, everything else equal, more likely to harbor informality, with an informal economy well above 40 percent of GDP.

\section{ROBUSTNESS TESTS}

\section{A. Estimating the Size of the Informal Economy Using Predictive Mean Matching}

Predictive Mean Matching (PMM), (Rubin, 1987) ${ }^{12}$ treats the empirical challenge in the estimation of the size of the informal economy as a missing data problem: for some countries, we have survey-based estimates of the size of the informal economy, ${ }^{13}$ for others, it is missing.

Missing data can result from three types of mechanisms: missing completely at random (MCAR), missing at random (MAR) or missing not at random (MNAR), (Little and Rubin, 1987). ${ }^{14}$ The PMM analysis assumes that for the informal economy, the mechanism is MAR. This means the following: the probability that an observation is missing can depend on observed co-variates of non-missing units and missing units, but it cannot depend on missing data, the size of the informal economy. In other words, we are assuming that the probability that a country is missing data on its informal economy can depend on characteristics relevant for the informal economy, but the size of the informal economy itself should not be a factor. This assumption can be challenged because one can argue that a large informal economy would be difficult to measure, resulting in missing data. Furthermore, a large informal economy can be associated with institutional weaknesses that would make it also less likely to be measured due to capacity constraints. However, when we look at the survey data available, we see that there are data available for large informal economies as well, such as Niger and Burundi. Therefore, at least in practice, the MAR assumption is somewhat validated, but would have to be checked through sensitivity analyses that would operate under MNAR.

The objective is to match the countries where data exist to the those where data are missing using characteristics that would be relevant to the size of the informal economy.

One of the challenges inherent in the empirical problem of estimating the size of the informal economy is that, for many countries, this is hard to estimate due to institutional capacity constraints. The informal economy is complex, encompassing many related factors that in any estimation procedure may produce problems of endogeneity and other empirical challenges. A principal constraint in this exercise is that those countries for which some estimation of the informal economy is available are not very similar to countries where this is missing, incidentally, the very countries where we are trying to produce an estimate in Sub-Saharan Africa.

\footnotetext{
12 Rubin, D.B. "Multiple Imputation for Nonresponse in Surveys", Wiley 1987..

13 There were 49 countries that were identified to have survey-based estimates of the size of their informal economies, including 9 in Sub-Saharan Africa.

${ }^{14}$ Little, Roderick, JA and Rubin, B. Donald, "Statistical Analysis with Missing Data", Wiley Series in Probability and Statistics, Second Edition, 2002.
} 
Predictive Mean Matching (PMM) circumvents this challenge somewhat by producing multiple datasets using its Bayesian setup. Therefore, where we lack the data for similar countries, the method is able to compensate by taking advantage of the inherent uncertainty associated with a missing data problem.

The other advantage of the PMM method is that in its actual estimation step, it is nonparametric. It does not suffer from any of the problems associated with a regular regression method in which dissimilar countries would be estimated using the same co-variates, and assuming linear extrapolations across co-variate distributions that may be different and far apart from each other. The principle of similarity in PMM avoids this fundamental problem: it matches countries lacking data to countries that have the data based on their similarity. But how is this similarity itself estimated? This is the crux of the methodology. Similar to PMM, Propensity Score Matching (PSM) is also a promising candidate. However, the constraint with PSM in this case is that not enough similar observations are matched to be able to then run separate regressions or even make non-parametric estimates for each group due to the number of estimations that are necessary to make.

The similarity principle for PMM is established using a linear regression. Here, we estimate the following simple OLS model:

$$
\begin{gathered}
Y_{i t}=\alpha+\beta_{g_{e 0}} * G E_{0}+\beta_{r q} * R Q+\beta_{c} * C+\beta_{\overline{r o l}} * \beta * R O L+\beta_{b f} * B F+\beta_{s e} * S E+\beta_{H D I} \\
* H D I+\beta_{E} * E
\end{gathered}
$$

Where $\mathrm{Y}$ is the size of the informal economy as percent of GDP, GE is government effectiveness index, RQ is a regulatory quality index, $\mathrm{C}$ is a corruption index, ROL is a rule of law index, BF is a business freedom index, SE is self-employment levels, HDI is the Human Development Index, and $\mathrm{E}$ is an education variable.

The distinctive feature of the PMM is that this regression is not actually used for the estimation of the size of the informal economy, but rather as a matching tool. For this we have the following eight stages that are computed using the SAS Proc MI procedure ${ }^{15}$ :

1) A random draw is made from the posterior predictive distribution of the estimated covariate coefficient matrix $\beta$. $^{-}$, resulting in a new co-variate coefficient matrix $\beta_{\bar{*}}$.

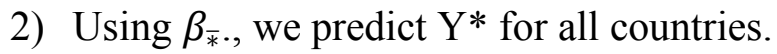

3) The algorithm then identifies countries where we had actual Yi and whose predicted $\mathrm{Y}^{*}$, are closest to the predicted $\mathrm{Y}^{*}$ of the countries missing the data. Hence we have matches between $\mathrm{Y}^{*}$ iobs and $\mathrm{Y}^{*}$ imiss: predicted values for the outcome variable originally missing and originally having an estimate of the size of the informal economy.

${ }^{15}$ SAS, STAT 14.1 User's Guide The MI Procedure, SAS Institute, 2015. 
4) Each country missing the data is assigned to a group that has similar countries having the data from the previous procedure.

5) In each group, the MI algorithm randomly selects a match to the countries originally missing the outcome, and assigns the observed outcome from the match to be the estimated outcome variable for the country missing the outcome.

6) Steps 1-5 are repeated five times, generating five distinct datasets with imputed values of the informal economy, mimicking the variability inherent due to the uncertainty associated with the missing data mechanism.

7) To produce a final estimate, we take the average of the five datasets for the size of the informal economy. ${ }^{16}$

The results are broadly consistent with the rankings produced by the MIMIC method (See Table 4).

\section{B. Estimating the Size of the Informal Economy Using Traditional MIMIC Approach (a la Schneider, 2010)}

The results are also robust to estimations consistent with the traditional MIMIC approach. This robustness test is based on Schneider (2010) and relies on a set of variables that includes the use of GDP per capita and growth of GDP per capita (instead of night lights)

The cause variables:

Tax burden or government distortions: The tax and social security burdens are among the main causes of the informal economy. The larger the difference between the total cost of labor in the official economy and after-tax earnings, the greater the incentive to avoid this by joining the informal economy. We consider two variables to proxy for the effects of government taxation and spending on the informal economy the share of government consumption in GDP and the fiscal freedom index from the Heritage Foundation. A larger government will be required to raise more taxes, which distort economic activity and push economic agents from the formal to informal sector. The fiscal freedom index uses equally weighted scores from the top marginal tax rate on personal and corporate income, as well as the share of tax burden in GDP. High marginal rates on personal income will push workers towards the informal sector, just as high marginal rates on corporate income would encourage businesses to move activity to the informal sector.

\footnotetext{
${ }^{16}$ Here, we can of course weigh these datasets based on a separate estimation procedure that would give certain "matches" more weight. For example, we could separately estimate a propensity score for each country, and use the propensity scores to weigh the matches in each dataset. For simplicity, in this paper, we use a simple average.
} 
Institutional quality: Institutional quality has a strong bearing on competitiveness and growth. A weak judiciary system, excessive bureaucracy, lack of transparency, and directed credit to connected borrowers and strategic enterprises exacerbate the incentives to informality. Furthermore, the stronger the enforcement capability and quality of government are, the lower the expected size of the informal economy. We consider two measures of institutional quality from the World Bank Worldwide Governance Indicators, which are compiled from a number of primary sources. The rule of law index "captures perceptions of the extent to which agents have confidence in and abide by the rules of society" so that in countries with higher scores economic agents will understand "the rules of the game" and can interact in the market with confidence. The control of corruption index "captures perceptions of the extent to which public power is exercised for private gain" and a high score represents economic agents having confidence that authorities will not abuse their position in dealings. We additionally consider a measure from Political Risk Services, namely, government stability. On top of honest officials and standard interpretation of the law, a more stable government provides the basis for confidence in participating in economic markets.

Size of the market and economic activity: In richer countries, it is likely to prove more difficult to move some economic activity from the formal to the informal economy. We control for this by including GDP per capita at purchasing power parity in our model. Additionally, as economies become more interconnected and trade more with their neighbors and other countries, this trade is hard to hide from authorities as it has to enter the country through some means, which is likely tracked by the fiscal authority or statistical agency. We thus include openness, measured as the percent of trade in GDP, as another cause in our model. Lastly, as the formal sector goes through the trough of a business cycle, workers may lose their preference for formal employment as jobs in that sector become more scarce and they shift to offering their labor to the informal economy. This suggests the unemployment rate would also be a cause of the informal economy.

Informal economy activities are also reflected in labor market and monetary indicators. Depending on data availability, most studies use the following indicators (see, for example, Abdih and Medina (2016), Loayza (1997), Schneider et al. (2010), and Vuletin (2009)):

Growth in GDP per capita: as economic activity moves from the formal to the informal sector, this would register in national accounts data as a decrease in GDP per capita.

Labor force participation rate: the proportion of the population that is economically active in the formal sector.

Monetary Indicators: Given that people who engage in shadow economy transactions do not want to leave traces, they conduct these activities in cash. Hence, most shadow economy activities are reflected in an additional use of cash (or currency). To take this into account, two indicators are used: (a) M0/M1: M0 corresponds to the currency 
outside the banks; the usual definition for M1 is M0 plus deposits. (b) Currency/M2: this corresponds to the currency outside the banks as a proportion of M2.

The results are depicted in Tables 5 and 6 . We find these results to be largely consistent with the previous MIMIC estimation. Table 5 shows the results using the entire sample, while Table 6 considers only developing countries.

For the causal variables, we find across all specifications in both tables that the size of government, GDP per capita, and the unemployment rate are statistically significant and consistently estimated. A one standard deviation increase in the size of government and the unemployment rate leads to an approximate 0.09 increase in the size of informal economic activity. For a one standard deviation increase in GDP per capita, the estimated decrease in informal economic activity ranges from 0.3 to 0.4 . For the total sample, the other causal variables are found to be statistically significant and in line with our priors that greater fiscal freedom, greater rule of law, more control on corruption, greater government stability, and more trade openness all lead to less informal economic activity.

For the developing economies sample, we find no significance on the rule of law and control of corruption. This suggests that for developing countries, informal activity depends more on the stability of the government than whether the "rules of the game" are consistently applied and there is no corruption. For the indicator variables, we find more informal economic activity has a statistically significant negative effect on both labor force participation and GDP per capita growth across all specifications for both samples.

\section{Comparison with Countries' National Accounts Statistics}

Most countries around the world have estimates for the size of the informal economy, and countries in Sub-Saharan Africa are not the exception. In this section, we test MIMIC results against the estimates of Statistical Agencies of eight sub-Saharan African countries for which information is readily available. The rank correlation is high —about 85 percent—between MIMIC results and these estimates (See Table 7).

Although these agencies provide estimates of the size of the informal economy, the data generated by MIMIC is still useful. First, not all countries publish the information. Second, methodologies and sampling methods may affect the comparability of cross-country estimates. Finally, estimates may be rooted in approaches that fail to take account of recent 
changes in the domestic economy. In contrast, MIMIC produces panel data for most countries that is comparable and can be used to test statistical relationships.

\section{Conclusions}

This paper contributes to the literature and addresses concerns by generating robust estimates of the size of the informal economy in Sub-Saharan African countries. It does so by applying a variety of methodologies. Specifically, by:

(a) using a modified version of the standard Multiple Indicator-Multiple Cause (MIMIC) model. This version addresses endogeneity concerns to the use of GDP by using the light intensity approach instead of the GDP as an indicator variable as proxy for the size of the economy.

(b) estimating the size of the informal economy by using a completely independent method, the Predictive Mean Matching method (PMM) by Rubin (1987). This not only tests the robustness of the modified MIMIC by estimating, but also addresses a long and controversial discussion on how to calibrate the relative MIMIC estimates of the informal economy (compare Hashimzade and Heady (2016), Feige (2016a and 2016b), and Schneider (2016).

(c) comparing these results with the official estimations from countries' national account statistics.

Results suggest that there is significant heterogeneity in the size of informality in SSA, ranging from a low of 20 to 25 percent in Mauritius, South Africa and Namibia to a high of 50 to 65 percent in Benin, Tanzania and Nigeria. Additionally, that the informal economy in SubSaharan Africa remains among the largest in the world, although this share has been very gradually declining.

Results also suggest that broadly, informality seems to fall with the level of income likely reflecting higher government capacity and better incentives toward formality in higher income countries. Finally, this global trait also holds for Sub-Saharan Africa, as the informal economy averages 40 percent in the region's low income countries and 35 percent for its middle income countries. Nonetheless, a different characterization seems to trump those considerations: oil exporters and fragile countries are, everything else equal, more likely to harbor informality, with an informal economy well above 40 percent of GDP.

To verify the validity and robustness of the estimates, we have cross-checked them using an alternative and fully independent econometric approach, the Multiple Imputations Predictive Mean Matching (MIPMM), developed by Rubin D.B. The MIMIC results are found to be robust when cross-checked with MIPMM results. This alternative method treats informality as a missing data issue. The objective is to match the countries where data exist to those where data are missing by using characteristics that would be relevant to the size of the informal 
economy. ${ }^{17}$ When using this procedure, countries are ordered in groups based on the size of the informal economy. These groups are broadly aligned with MIMIC findings.

The robustness of MIMIC results is also checked against the estimates of Statistical Agencies of eight sub-Saharan African countries for which information is readily available. The rank correlation is high — about 80 percent - between MIMIC results and these estimates. Although these agencies provide estimates of the size of the informal economy, the data generated by MIMIC is still useful. First, not all countries publish the information. Second, methodologies and sampling methods may affect the comparability of cross-country estimates. Finally, estimates may be rooted in approaches that fail to take account of recent changes in the domestic economy. In contrast, MIMIC produces panel data for most countries that is comparable and can be used to test statistical relationships.

We believe this is the first time that such a combination of methodologies, which includes modified MIMIC using night lights, PMM, and countries' national accounts, has been used to generate robust estimates of the size of the informal economy.

Finally, regarding the policy implications of this paper, few studies have investigated some of the reasons for the variation in the size of the informal economy, which are then used to make some policy recommendations on how best to shift activity from the informal to the formal sector. The policy advice in these studies (See for example International Monetary Fund 2017) also emphasizes the importance of allowing informal activity to act as a social safety as this transition is likely to be long.

\footnotetext{
17 There were 49 countries that were identified to have survey-based estimates of the size of their informal economies, including nine in Sub-Saharan Africa.
} 


\section{REFERENCES}

Abdih Y., and L. Medina, 2016, "The informal economy in the Caucasus and Central Asia: size and determinants" in Arnis Sauka, Friedrich Schneider, and Colin C. Williams (Editors) Entrepreneurship and the Shadow Economy, Edward Elgar Publishing Inc (2016).

Boeschoten, W., and M. Fase, 1984, The Volume of Payments and the Informal Economy in the Netherlands 1965-1982, M. Nijhoff, Dordrecht.

Cagan, P., 1958, “The Demand for Currency Relative to the Money Supply," Journal of Political Economy, Vol. 66, pp. 302-28.

Contini, B., 1981, "Labor Market Segmentation and the Development of the Parallel Economy- the Italian Experience," Oxford Economic Papers, Vol. 33, pp. 401-12.

Del Boca, D., 1981, "Parallel Economy and Allocation of Time," Micros: Quarterly Journal of Microeconomics, Vol. 4, pp. 13-18.

Del Boca, D., and F. Forte, 1982, "Recent Empirical Surveys and Theoretical Interpretations of the Parallel Economy in Italy", in V. Tanzi (ed.) The Underground Economy in the United States and Abroad. Lexington: D.C. Heath, pp. 160-78.

Feige, E., 1979, “How Big is the Irregular Economy?” Challenge, Vol. 22, pp. 5-13. , 2005, "Overseas Holdings of U.S. Currency and the Underground Economy," Macroeconomics 0501022, EconWPA.

,2016a, Reflections on the Meaning and Measurement of Unobserved Economist: What Do We Really Know About the Shadow Economy?, Journal of Tax Ad-ministration 2/2, 2016, Special Issue: The Shadow Economy.

, 2016b, Professor Schneider's Shadow Economy (SSE): What Do We Re-ally Know? A Rejoinder., Journal of Tax Administration, 2/2, 2016.

Feldmann, H., 2009, - The Unemployment Effects of Labor Regulation Around the World,॥ Journal of Comparative Economics, Vol. 37 (1), pp. 76-90.

Feld, L. P. and F. Schneider, 2010, Survey on the shadow economy and undeclared earnings in OECD countries, German Economic Review, 11/2, pp. 109-49.

Gutmann, P., 1977, “Subterranean Economy,” Financial Analysis Journal, Vol. 33, pp. 2627.

Hashimzade, Niga and Hedy, Chris (2016), Reflections on the Meaning and Measurement of Unobserved Economies: An Editorial Comment, Journal of Tax Administration 2/2, 2016. 
International Monetary Fund, 2017, African Department Regional Economic Outlook, Chapter Three: The Informal Economy in Sub-Saharan Africa, May 2017, Washington DC.

Isachsen, A. and S. Strom, 1985, "The Size and Growth of the Hidden Economy in Norway", Review of Income and Wealth, Vol. 31, pp. 21-38.

Johnson, S., D. Kaufmann and A. Shleifer, 1997, "The Unofficial Economy in Transition," Brookings Papers on Economic Activity, Fall, Washington D.C.

Kaufmann, D. and A. Kaliberda, 1996, "Integrating the Unofficial Economy into the Dynamics of Post-Socialist Economies: A Framework of Analysis and Evidence", in B. Kaminski (ed.) Economic Transition in Russia and the New States of Eurasia. Armont, NY: M. E. Sharpe, Inc.

Langfeldt, E., 1984, “The Unobserved Economy in the Federal Republic of Germany”, in E. Feige (ed.) The Unobserved Economy (Cambridge: Cambridge University Press), pp. 236-60.

Little, Roderick, JA and Donald, Rubin, "Statistical Analysis with Missing Data", Wiley Series in Probability and Statistics, Second Edition, 2002.

Loayza, N., 1997, "The Economics of the Informal Sector: a Simple Model and Some Empirical Evidence from Latin America", World Bank Policy Research Working Paper, WPS 1727 (World Bank: Washington DC).

MacAfee, K., 1980, "A Glimpse of the Hidden Economy in the National Accounts", Economic Trends, Vol. 136, pp. 81-87.

Mogensen, G., H. Kvist, E. Körmendi, and S. Pedersen, 1995, “The shadow economy in Denmark 1994: Measurement and results," Study No. 3, Copenhagen: The Rockwool Foundation Research Unit.

O’Neill, D., 1983, "Growth of the Underground Economy 1950-81: Some Evidence from the Current Population Survey," Study for the Joint Economic Committee, 98:122; Washington: U.S. Congress, Joint Committee Print, U.S. Gov. Printing Office.

Portes, A., M. Castells and L. Benton, 1989, "World Underneath: The Origins, Dynamics, and Effects of the Informal Economy”, in Portes, A., M. Castells and L. Benton (eds.) The Informal Economy: Studies in Advanced and Less Developed Countries. Johns Hopkins University Press, Baltimore.

Rubin, D.B. “Multiple Imputation for Nonresponse in Surveys”, Wiley 1987.

Schneider, F., and D. Enste, 2000, "Shadow Economies: Size, Causes, and Consequences", Journal of Economic Literature, Vol. 38, pp. 77-114. 
SAS, STAT 14.1 User's Guide The MI Procedure, SAS Institute, 2015.

Schneider, F., 1997, "The Shadow Economies of Western Europe", Journal of the Institute of Economic Affairs, Vol. 17, pp. 42-48.

Schneider, F., and D. Enste, 2000, —Shadow Economies: Size, Causes, and Consequences, Journal of Economic Literature, Vol. 38, pp. 77-114.

, 2002, The Shadow Economy: An International Survey,

Cambridge: Cambridge University Press.

, 2010, —Shadow Economies All Over the World: New Estimates for 164 Countries from 1999 to 2007, World Bank Policy Research Working Paper 5356, (Washington: World Bank).

, 2016, Comment on Feige's Paper, Reflections on the Meaning and Measurement of Unobserved Economies: What Do We Really Know About the Shadow Economy?, Journal of Tax Administration Vol. 2/2.

Tanzi, V., 1980, “The Underground Economy in the United States: Estimates and Implications”, Banca Nazionale del Laboro, Vol. 135, pp. 427-53.

, 1983, "The Underground Economy in the United States: Annual Estimates, 19301980," IMF Staff Papers, Vol. 33, pp. 283-305.

Vuletin, G., 2009, "What is the Size of the Pie? Measuring the Informal Economy in Latin America and the Caribbean." Money Affairs, Vol. 21, pp. 161-191.

Witte, A., 1987, “The Nature and Extent of Unreported Activity: A Survey Concentrating on Recent U.S. Research," in Alessandrini, S. and B. Dallago (eds.) The Unofficial Economy: Consequences and Perspectives in Different Economic Systems. Gower, Aldershot.

Yoo, T., and J. Hyun, 1998, "International Comparison of the Black Economy: Empirical Evidence Using Micro-Level Data", Unpublished paper presented at the 1998 Congress of the International Institute of Public Finance, Cordoba, Argentina. 
Table 1. MIMIC Model Estimation Results: All Countries

\begin{tabular}{|c|c|c|c|c|c|c|}
\hline & 1 & 2 & 3 & 4 & 5 & 6 \\
\hline \multicolumn{7}{|l|}{ Causes } \\
\hline Trade Openess & $-0.172^{* * *}$ & $-0.167 * * *$ & $-0.106 * * *$ & $-0.178^{* * *}$ & $-0.175^{* * *}$ & $-0.161^{* * *}$ \\
\hline Unemployment Rate & $0.062^{* *}$ & $0.061^{* *}$ & 0.008 & $0.067^{* *}$ & $0.068^{* *}$ & $0.056^{* *}$ \\
\hline Size of Government & $0.106 * * *$ & $0.101 * * *$ & $0.036^{*}$ & & & \\
\hline Fiscal Freedom & & & & $-0.15^{* * *}$ & $-0.153^{* * *}$ & $-0.162 * * *$ \\
\hline Rule of Law & $-0.065^{* *}$ & & & $-0.068 * *$ & & \\
\hline Control of Corruption & & -0.026 & & & -0.035 & \\
\hline Government Stability & & & $-0.183^{* * *}$ & & & $-0.132^{* * *}$ \\
\hline \multicolumn{7}{|l|}{ Indicators } \\
\hline Currency & 1 & 1 & 1 & 1 & 1 & 1 \\
\hline Labor Force Participation Rate & $-0.457^{* * *}$ & $-0.503 * * *$ & $-0.478 * * *$ & $-0.226^{*}$ & $-0.244^{*}$ & $-0.23 * *$ \\
\hline Lights (GDP) & $-0.346 * * *$ & $-0.372 * * *$ & $-1.838^{* * *}$ & $-0.275^{* * *}$ & $-0.289 * * *$ & $-0.661 * * *$ \\
\hline \multicolumn{7}{|l|}{ Statistical Tests } \\
\hline RMSEA & 0.023 & 0.027 & 0.079 & 0.052 & 0.053 & 0.082 \\
\hline Chi-square & 125.015 & 116.891 & 548.593 & 158.781 & 151.93 & 307.091 \\
\hline Observations & 1341 & 1336 & 1767 & 1211 & 1210 & 1498 \\
\hline Countries & 148 & 148 & 120 & 139 & 139 & 116 \\
\hline
\end{tabular}

Note: ${ }^{* * *} \mathrm{p}<0.01,{ }^{* *} \mathrm{p}<0.05,{ }^{*} \mathrm{p}<0.1$

Table 2. MIMIC Model Estimation Results: Developing Countries

\begin{tabular}{|c|c|c|c|c|c|c|}
\hline & 1 & 2 & 3 & 4 & 5 & 6 \\
\hline \multicolumn{7}{|l|}{ Causes } \\
\hline Trade Openess & $-0.159 * * *$ & $-0.155^{* * *}$ & $-0.076 * * *$ & $-0.139 * * *$ & $-0.136^{* * *}$ & $-0.08 * * *$ \\
\hline Unemployment Rate & 0.029 & 0.029 & -0.007 & 0.047 & 0.047 & 0.006 \\
\hline Size of Government & $0.094 * *$ & $0.092 * *$ & $0.026^{*}$ & & & \\
\hline Fiscal Freedom & & & & $-0.129 * * *$ & $-0.128 * * *$ & $-0.104^{* * *}$ \\
\hline Rule of Law & -0.021 & & & -0.009 & & \\
\hline Control of Corruption & & -0.004 & & & -0.009 & \\
\hline Government Stability & & & $-0.192 * * *$ & & & $-0.164^{* * *}$ \\
\hline \multicolumn{7}{|l|}{ Indicators } \\
\hline Currency & 1 & 1 & 1 & 1 & 1 & 1 \\
\hline Labor Force Participation Rate & $-0.419 * *$ & $-0.427^{* *}$ & $-0.518^{* * *}$ & $-0.311^{*}$ & $-0.313^{*}$ & $-0.323 * *$ \\
\hline Lights (GDP) & $-0.636 * * *$ & $-0.657 * * *$ & $-2.389 * * *$ & $-0.694 * * *$ & $-0.704 * * *$ & $-1.426 * * *$ \\
\hline \multicolumn{7}{|l|}{ Statistical Tests } \\
\hline RMSEA & 0.01 & 0.014 & 0.072 & 0.04 & 0.04 & 0.073 \\
\hline Chi-square & 89.64 & 87.74 & 527 & 113.669 & 110.397 & 290.032 \\
\hline Observations & 957 & 952 & 1304 & 850 & 849 & 1088 \\
\hline Countries & 103 & 103 & 83 & 96 & 96 & 80 \\
\hline
\end{tabular}


Table 3. MIMIC Model Estimation Results: Advanced Countries

\begin{tabular}{|c|c|c|c|c|c|c|}
\hline & 1 & 2 & 3 & 4 & 5 & 6 \\
\hline \multicolumn{7}{|l|}{ Causes } \\
\hline Trade Openess & 0.132 & $0.204 * *$ & $0.229 * * *$ & 0.075 & 0.108 & $0.174 * *$ \\
\hline Unemployment Rate & $-0.352 * * *$ & $-0.36 * * *$ & $-0.41 * * *$ & $-0.3^{* * *}$ & $-0.295^{* * *}$ & $-0.34 * * *$ \\
\hline Size of Government & -0.098 & $-0.158^{*}$ & $-0.165^{* *}$ & & & \\
\hline Fiscal Freedom & & & & $-0.247^{* * *}$ & $-0.293 * * *$ & $-0.23 * * *$ \\
\hline Rule of Law & $-0.24 * * *$ & & & $-0.186 * *$ & & \\
\hline Control of Corruption & & $-0.117^{*}$ & & & -0.092 & \\
\hline Government Stability & & & -0.064 & & & 0.024 \\
\hline \multicolumn{7}{|l|}{ Indicators } \\
\hline Currency & 1 & 1 & 1 & 1 & 1 & 1 \\
\hline Labor Force Participation Rate & $-0.329 *$ & $-0.363 *$ & $-0.462 * * *$ & $-0.308 *$ & $-0.329 * *$ & $-0.316^{* *}$ \\
\hline Lights (GDP) & $0.467^{* *}$ & $0.366^{*}$ & -0.0661817 & $0.553 * * *$ & $0.51^{* * *}$ & $0.381^{* *}$ \\
\hline \multicolumn{7}{|l|}{ Statistical Tests } \\
\hline RMSEA & 0.068 & 0.067 & 0.122 & 0.052 & 0.056 & 0.086 \\
\hline Chi-square & 76.456 & 64.922 & 136.547 & 89.16 & 82.642 & 113.695 \\
\hline Observations & 189 & 189 & 302 & 189 & 189 & 263 \\
\hline Countries & 24 & 24 & 24 & 24 & 24 & 24 \\
\hline
\end{tabular}

Note: $* * * \mathrm{p}<0.01, * * \mathrm{p}<0.05, * \mathrm{p}<0.1$ 
Table 4. Predictive Mean Matching (PMM) Resuls on the Size of the Informal Economy in SSA (percent of GDP) compared to MIMIC

\begin{tabular}{ll}
\hline Low-Size Countries (0-20 percent) & High-Size Countries ( $\mathbf{4 0}$ percent) \\
Mauritus & Congo, Republic of \\
South Africa & Togo* \\
Botswana & Guinea-Bissau \\
Lesotho & Nigeria* \\
Swaziland & Mali \\
& Senegal \\
Middle-Size Countries (20-40 percent) & Comoros \\
Cabo Verde & Congo, Democratic Republic of \\
Namibia & Zambia \\
Kenya & Ghana \\
Zimbabwe & Guinea \\
Eritrea & Tanzania \\
Gabon & Ethiopia \\
The Gambia & Mauritania \\
Uganda & Central African Republic \\
Sierra Leone* & Angola \\
Cameroon* & Côte D'lvoire \\
Malawi & Liberia \\
& Madagascar \\
& Equatorial Guinea \\
& Niger* \\
& Mozambique \\
& Burkina Faso \\
& Chad \\
& Burundi* \\
\hline
\end{tabular}

Sources: Survey estimates and Predictive Mean Matching Analysis

*Based on survey estimates. 
Table 5. MIMIC Model Estimation Results: All Countries

\begin{tabular}{|c|c|c|c|c|c|}
\hline & 1 & 2 & 3 & 4 & 5 \\
\hline \multicolumn{6}{|c|}{ Causes } \\
\hline Size of Government & $0.083 * * *$ & $0.091 * * *$ & $0.091^{* * *}$ & $0.1 * * *$ & $0.096 * * *$ \\
\hline GDP per capita & $-0.361 * * *$ & $-0.321 * * *$ & $-0.33 * * *$ & $-0.433 * * *$ & $-0.337 * * *$ \\
\hline Unemployment Rate & $0.06 * *$ & $0.076 * * *$ & $0.078 * * *$ & $0.054 * *$ & $0.077^{* * *}$ \\
\hline Fiscal Freedom & $-0.144 * * *$ & & & & \\
\hline Rule of Law & & $-0.05 * *$ & & & \\
\hline Control of Corruption & & & $-0.05 * *$ & & \\
\hline Government Stability & & & & $-0.054 * *$ & \\
\hline Openness & & & & & $-0.126 * * *$ \\
\hline \multicolumn{6}{|c|}{ Indicators } \\
\hline Currency & 1 & 1 & 1 & 1 & 1 \\
\hline Labor Force Participation Rate & $-0.326 * * *$ & $-0.52 * * *$ & $-0.516 * * *$ & $-0.454 * * *$ & $-0.45^{* * *}$ \\
\hline Growth of GDP per capita & $-0.227 * * *$ & $-0.261 * *$ & $-0.27 * *$ & $-0.383 * * *$ & $-0.423 * * *$ \\
\hline \multicolumn{6}{|c|}{ Statistical Tests } \\
\hline RMSEA & 0.08 & 0.076 & 0.08 & 0.068 & 0.078 \\
\hline Chi-square & 126.06 & 95.491 & 105.627 & 95.917 & 149.011 \\
\hline Observations & 2327 & 1917 & 1912 & 2355 & 2907 \\
\hline Countries & 144 & 152 & 152 & 123 & 151 \\
\hline
\end{tabular}

Note: ${ }^{* *} \mathrm{p}<0.01, * * \mathrm{p}<0.05, * \mathrm{p}<0.1$

Table 6. MIMIC Model Estimation Results: Developing Countries

\begin{tabular}{|c|c|c|c|c|c|}
\hline & 1 & 2 & 3 & 4 & 5 \\
\hline \multicolumn{6}{|c|}{ Causes } \\
\hline Size of Government & $0.088 * * *$ & $0.094 * * *$ & $0.094 * * *$ & $0.097 * * *$ & $0.1 * * *$ \\
\hline GDP per capita & $-0.329 * * *$ & $-0.279 * * *$ & $-0.282 * * *$ & $-0.382 * * *$ & $-0.317 * * *$ \\
\hline Unemployment Rate & $0.085^{* * *}$ & $0.095^{* * *}$ & $0.094 * * *$ & $0.068 * * *$ & $0.084 * * *$ \\
\hline Fiscal Freedom & $-0.141 * * *$ & & & & \\
\hline Rule of Law & & -0.027 & & & \\
\hline Control of Corruption & & & -0.032 & & \\
\hline Government Stability & & & & $-0.065 * * *$ & \\
\hline Openness & & & & & $-0.136 * * *$ \\
\hline \multicolumn{6}{|c|}{ Indicators } \\
\hline Currency & 1 & 1 & 1 & 1 & 1 \\
\hline Labor Force Participation Rate & $-0.286 * * *$ & $-0.392 * * *$ & $-0.4 * * *$ & $-0.5^{* * *}$ & $-0.458 * * *$ \\
\hline Growth of GDP per capita & $-0.422 * * *$ & $-0.445 * * *$ & $-0.447 * * *$ & $-0.573 * * *$ & $-0.561 * * *$ \\
\hline \multicolumn{6}{|c|}{ Statistical Tests } \\
\hline RMSEA & 0.075 & 0.083 & 0.084 & 0.059 & 0.071 \\
\hline Chi-square & 81.13 & 81.39 & 82.614 & 55.593 & 91.738 \\
\hline Observations & 1620 & 1329 & 1324 & 1710 & 2085 \\
\hline Countries & 98 & 106 & 106 & 85 & 105 \\
\hline
\end{tabular}

Note: $* * * \mathrm{p}<0.01, * * \mathrm{p}<0.05, * \mathrm{p}<0.1$ 
Table 7. Comparison between National Accounts Statistics and MIMIC Results

\begin{tabular}{lcc}
\hline \multicolumn{1}{c}{ Country } & National Accounts Statistics & MIMIC \\
\hline Benin & 55.6 & 49.0 \\
Mali & 55.0 & 40.4 \\
Guinea-Bissau & 53.4 & 38.0 \\
Guinea & 48.1 & 37.0 \\
Senegal & 47.5 & 40.0 \\
Burkina Faso & 43.1 & 32.0 \\
Togo & 40.1 & 28.0 \\
Cote d'Ivoire & 34.0 & 35.0 \\
\hline
\end{tabular}

Correlation: 0.73

Spearman's Rank Correlation: $0.857^{* * *}$ 
Figure 1. Informal Economy Estimation: The MIMIC Model

$\underline{\text { Causes }}$

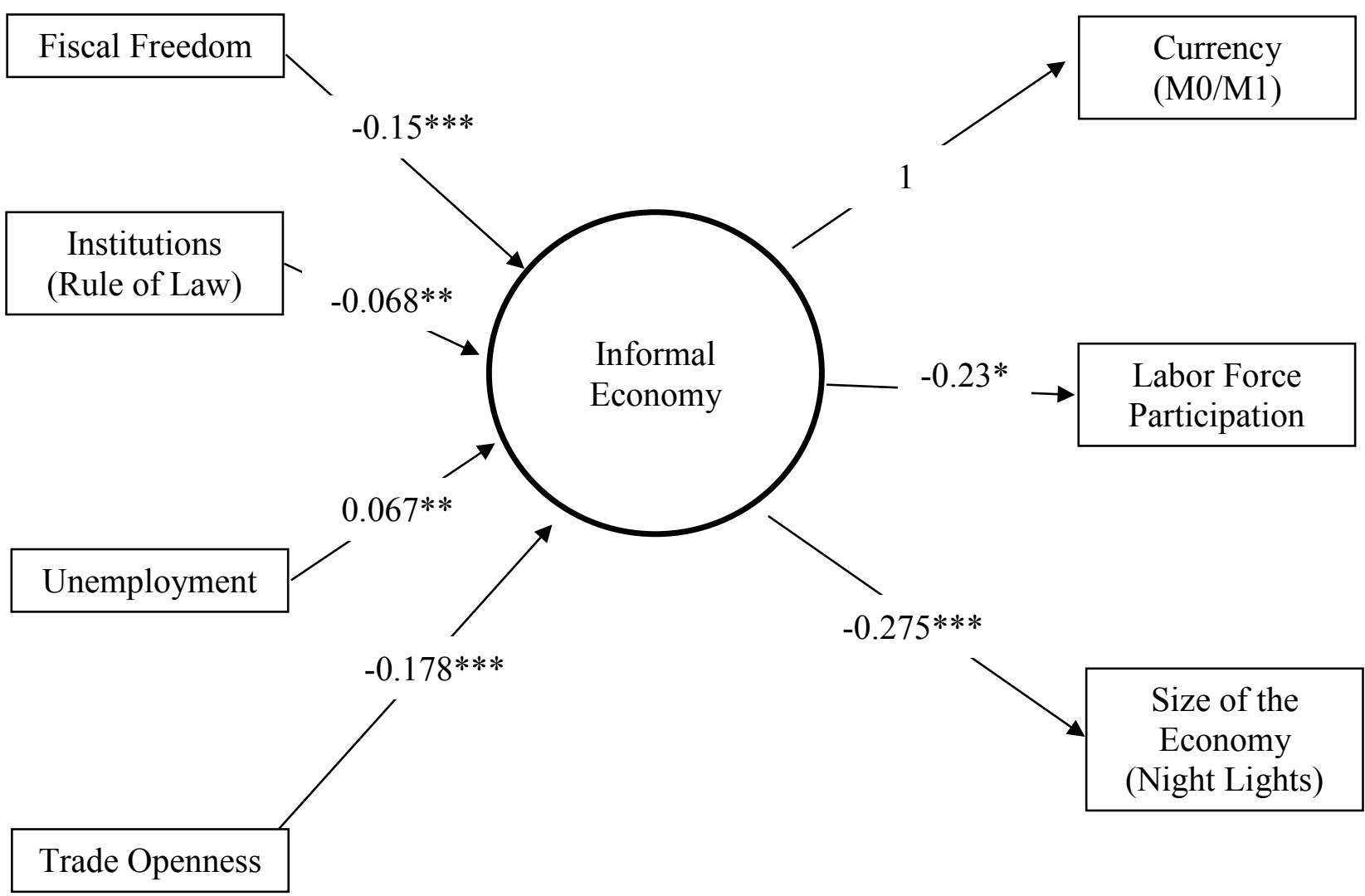

RMSEA: 0.052

Chi-Square: 158.781

Observations: 1211

Countries: 139 
Figure 2: The informal Economy in SSA, 2010 to 2104 average as a Share of GDP

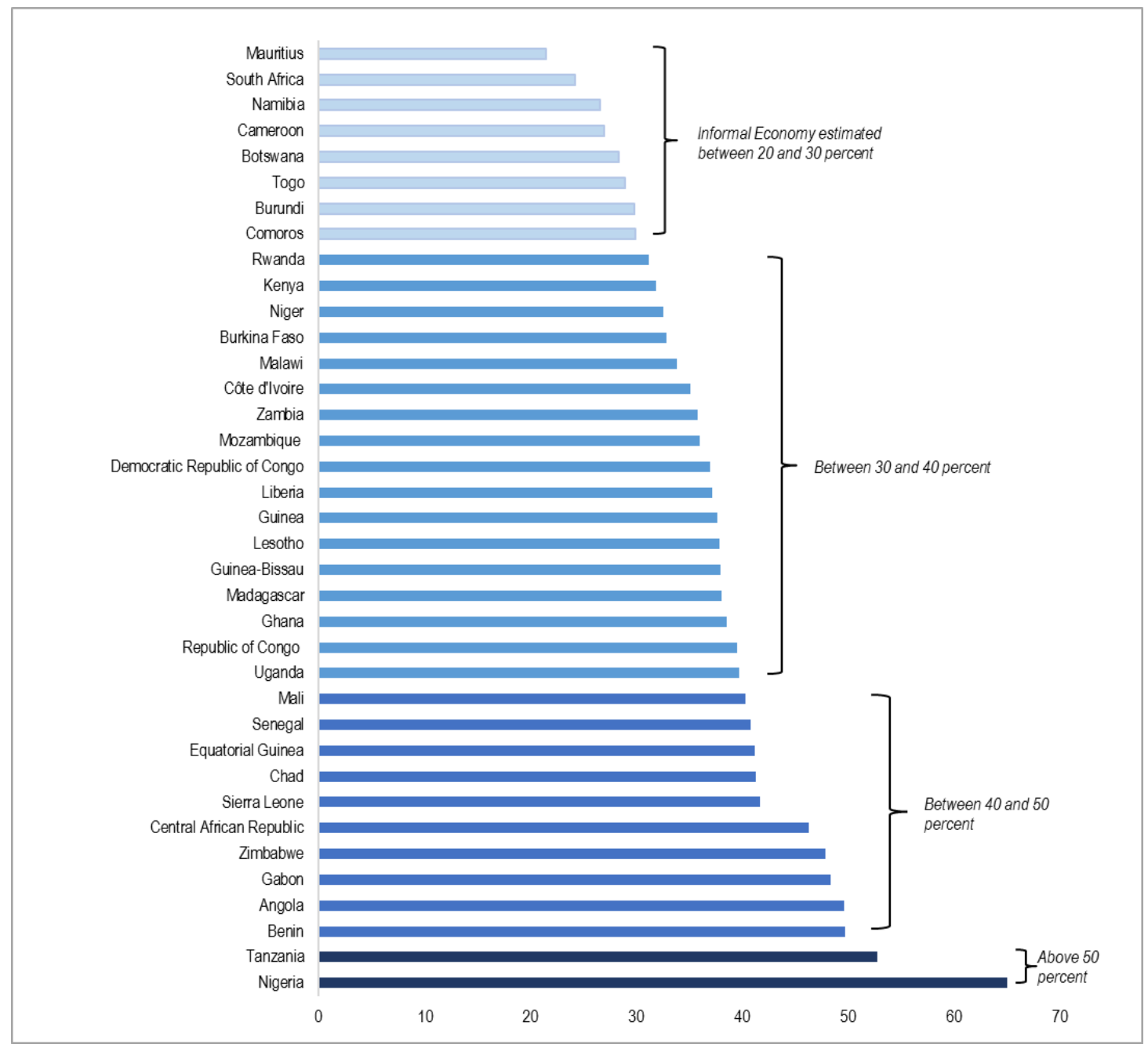


Figure 3. Informal Economy Around the World.

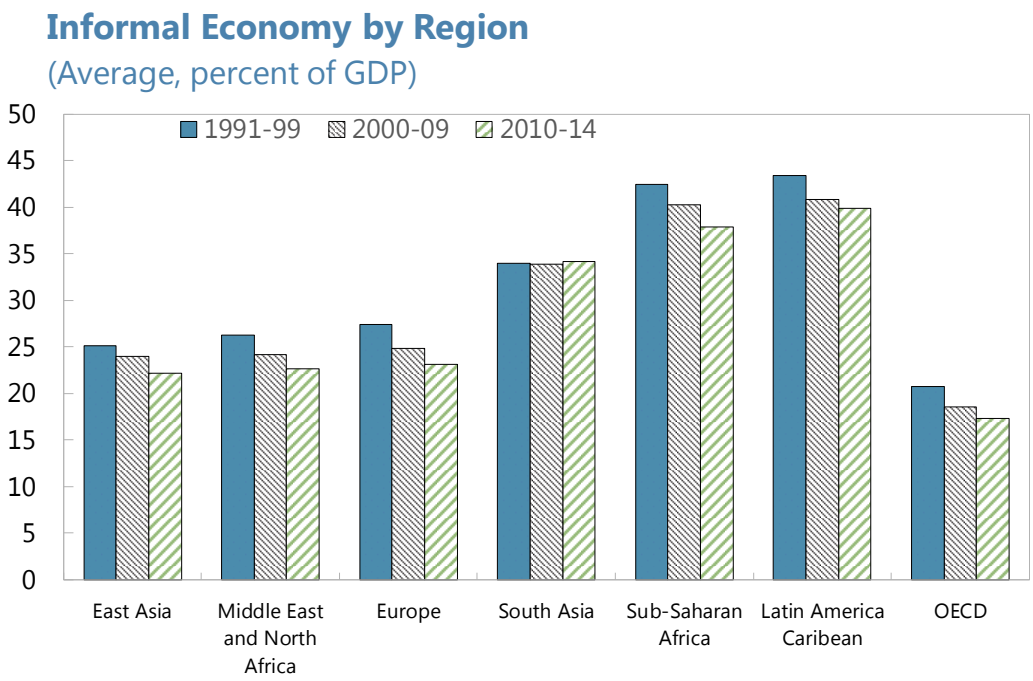

Informal Economy by Income Level (Average, percent of GDP)

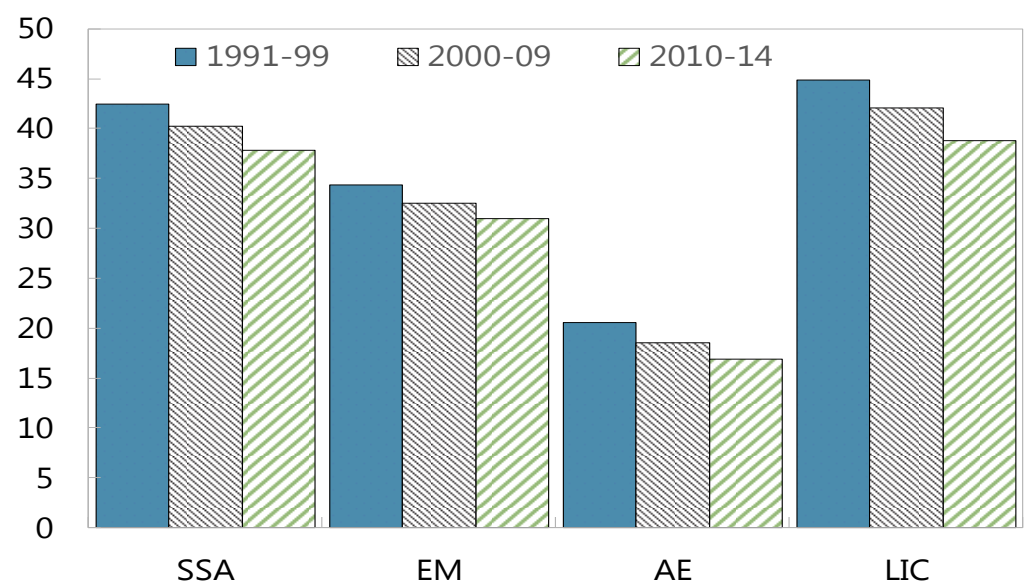

Informal Economy in Sub-Saharan Africa (Average, percent of GDP)

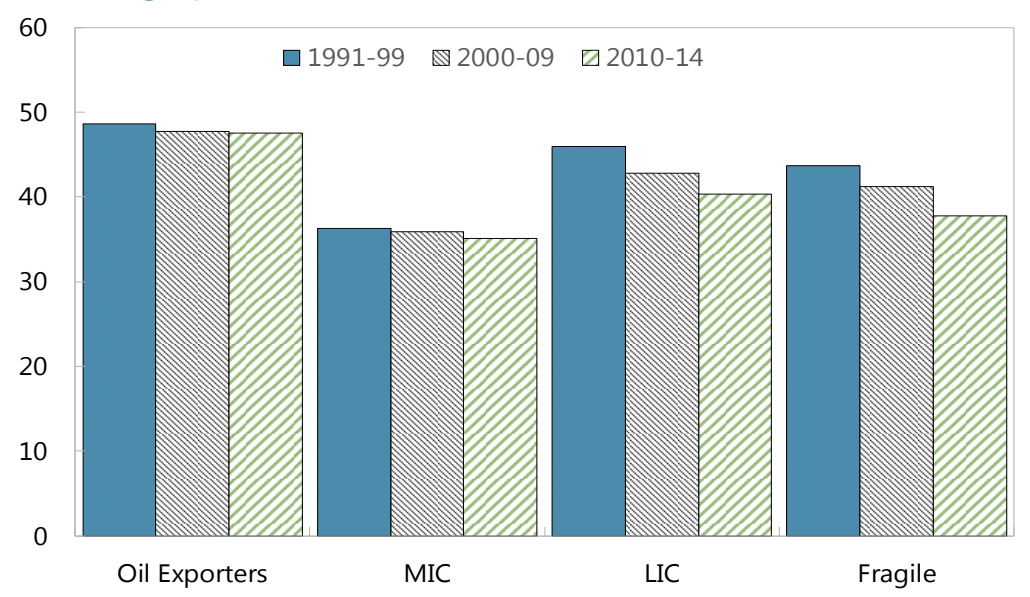

